\title{
Approaches to the modulation of abdominal pain
}

\author{
Emeran A Mayer $\mathrm{MD}^{1}$, Tony Lembo $\mathrm{MD}^{2}$, Lin Chang $\mathrm{MD}^{1}$
}

EA Mayer, T Lembo, L Chang. Approaches to the modulation of abdominal pain. Can J Gastroenterol 1999;13(Suppl A): 66A-70A. Despite their high prevalence and significant economic impact on the health care system, functional gastrointestinal disorders have evaded successful therapy. Conventional medical therapies are based on inadequate disease models, and the great majority of published treatment trials are flawed in their design, permitting no conclusions to be drawn about the true efficacy of any particular treatment. During the past several years, a new, comprehensive disease model based on alterations in brain-gut interactions has rapidly evolved. Even though the precise mechanisms and sites underlying these alterations remain incompletely understood, plausible targets for the development of effective pharmacological treatments are receptors on peripheral terminals of visceral afferent nerves (opioids and serotonin), ion channels and receptors on dorsal horn neurons within the spinal cord (opioids, glutamate, calcitonin gene-related peptide and neurokinin-1), and supraspinal targets in the brainstem within the limbic system and in the prefrontal cortex (serotonin, catecholamines, dopamine and acetylcholine). Regardless of the primary pathophysiology underlying functional gastrointestinal disorders (ie, central versus peripheral), different pharmacological strategies targeted at different sites in the periphery or within the central nervous system may become effective therapies in the future.

Key Words: Functional gastrointestinal disorders, Irritable bowel syndrome, Treatment

\section{Approches face à la douleur abdominale}

RÉSUMÉ : Malgré leur forte prévalence et leur impact économique significatif sur le système de soins de santé, les troubles gastro-intestinaux fonctionnels ne sont toujours pas traités avec tout le succès voulu. Les traitements médicamenteux classiques se fondent sur des modèles pathologiques inadéquats et la grande majorité des essais thérapeutiques publiés comportent des lacunes sur le plan de leur modélisation qui ne permettent pas de conclure à l'efficacité réelle de l'un ou l'autre des traitements. Au cours des quelques dernières années, un nouveau modèle global basé sur des altérations des interactions entre le cerveau et le système digestif a rapidement évolué. Bien que les mécanismes et les sites précis en cause dans ces altérations restent très peu compris, les cibles possibles des traitements pharmacologiques efficaces à venir sont les récepteurs des terminaisons périphériques des nerfs afférents viscéraux (opiacés et sérotonine), les canaux ioniques et les récepteurs situés sur les neurones de la corne supérieure de la moelles. À l'intérieur de la moelle épinière (opiacés, glutamate, peptides liés au gène de la calcitonine et neurokinine-1) et les cibles supra-spinales du tronc cérébral à l'intérieur du système limbique et dans le cortex pré-frontal (sérotonine, catécholamine, dopamine et acétylcholine). Indépendamment de la physiopathologie primaire sous-jacente dans les troubles gastro-intestinaux fonctionnels (c'est-à-dire central versus périphérique), différentes stratégies pharmacologiques visant différents sites à la périphérie ou à l'intérieur du système nerveux central pourraient devenir des thérapeutiques efficaces à l'avenir.

\section{EVOLVING DISEASE MODEL FOR FUNCTIONAL GASTROINTESTINAL DISORDERS}

While the reported alterations in gastrointestinal motility or visceral sensation by themselves do not explain the full clinical presentation of functional gastrointestinal disorders
(FGD), a multicomponent model of FGD, similar to models of other chronic illnesses involving physiological, affective, cognitive and behavioural factors can be formulated. The importance of each factor in the generation of FGD symptoms may vary from person to person. Behavioural factors

\footnotetext{
${ }^{1}$ UCLA/CURE Neuroenteric Disease Program, Department of Medicine, Physiology and Brain Research Institute, UCLA School of Medicine, Los Angeles, California; ${ }^{2}$ Beth Israel Deconnes Hospital, Boston, Massachusetts, USA

Correspondence: Dr EA Mayer, UCLA/CURE Neuroenteric Disease Program, WLA VA Medical Center, Building 115, Room 223,

11301 Wilshire Boulevard, Los Angeles, California 90073, USA. Telephone 310-312-9276, fax 310-794-2864, e-mail emayer@ucla.edu
} 


\section{COPYRIGHT PULSUS GROUP INC, = DO NOT COPY}

such as stressful life events are reported by up to $60 \%$ of irritable bowel syndrome (IBS) patients to be associated with the first onset or the exacerbation of IBS symptoms (1). Cognitive factors such as inappropriate coping styles, illness behaviour and inappropriate concepts about disease, nutrition and medications are common in FGD patients. These factors, in turn, determine the response to and the ability to cope with stressors related to either symptoms or stressful life events. Cognitive factors have a prominent influence on health care use and clinical outcomes. Affective factors, primarily in the form of anxiety, panic disorder and depression, are present in a large percentage of FGD patients seeking health care. Physiological factors implicated in the generation of FGD symptoms include hypersensitivity of the gastrointestinal tract to normal events; autonomic dysfunction including altered intestinal motility response to stress, anger and food intake; changes in fluid and electrolyte processing by the bowel; and alterations in sleep (2).

\section{ETIOLOGICAL MODEL FOR FGD}

Current evidence is consistent with an etiological model for FGD that assumes a predisposition of the nervous system in addition to specific environmental trigger factors. The predisposition may occur in the form of genetic factors or early life events, including perinatal events. The trigger factors may occur in the form of psychosocial stressors or physical stressors (gastroenteric infection, inflammation or tissue irritation).

Genetic factors: Recent data suggest that genetic predisposition may contribute to the development of IBS in some patients. Symptoms consistent with IBS are more common in first-degree relatives but not in spouses of subjects with IBS (3). Additionally, in a study of twin pairs in Australia, a proportion of the incidence of IBS in both twins was felt to be due to genetic rather than environmental factors (4). Further studies are needed to differentiate the effect of parent behaviour and family environment from that of genetic factors.

Perinatal events: Perinatal events may play a role in altering the nervous system in a way that makes the individual more sensitive to internal events, and more prone to central dysregulation of intestinal motor and secretory function. The nervous system is more vulnerable during pre- and early postnatal periods to perturbations, and changes occurring during this period may have long lasting effects due to neuroplastic changes in the central nervous system (CNS). Such perinatal events may occur as tissue irritation from gastroesophageal reflux disease, intestinal inflammation due to food intolerances and allergies, or neuroendocrine changes related to stress. Such neuroendocrine correlates of stress may be transmitted from the mother via increased cortisol and catecholamine levels in breast milk, or they may be generated by the newborn itself. Recent animal experimental data have demonstrated profound, long lasting changes in the nervous system in the form of hyperresponsiveness, irritability and predisposition to affective disorders in response to such perinatal stressors $(5,6)$.
Chronic psychosocial stressors: Stressful life events are often reported by patients to precede the onset or exacerbation of IBS symptoms. In a questionnaire study of 135 patients with IBS and 654 controls, $73 \%$ of the IBS group and $54 \%$ of the control group reported that stress altered their stool pattern, while $84 \%$ of the IBS group and $68 \%$ of the control group reported that stress led to abdominal pain. Stress also correlates with the frequency of bowel symptoms, the number of disability days and the number of physician visits.

Acute, life-threatening stressors (post-tramautic stress disorder): A history of severe emotional trauma such as physical and sexual abuse, especially when incurred during childhood, is associated with an increased risk of developing IBS. In one study at the University of North Carolina, 53\% of women with IBS gave a history of abuse in comparison with $37 \%$ of women with structural gastrointestinal diagnoses (7). However, more recent studies indicate that only acute stressful events associated with a direct threat to an individual's life are associated with a higher incidence of FGD $(8,9)$.

Physical stressors: IBS symptoms occur as approximately one-third of patients' symptoms following acute gastrointestinal infections and often persist for years following complete resolution of the infection. On the other hand, only a small percentage of all IBS patients present with such a history. A prospective study found that psychometric scores for anxiety, depression, somatization and neurotic traits were higher in individuals who developed prolonged IBS symptoms following acute gastroenteritis than in patients who returned to normal bowel function after acute gastroenteritis. This suggests that in predisposed individuals only, enteric infections and, presumably, other causes of mucosal irritation can precipitate IBS symptoms that may persist long after infection (or inflammation) has been resolved. That affective disorders appear to be part of this predisposition is consistent with CNS alterations playing a role in the etiology of IBS.

\section{THERAPEUTIC APPROACHES}

A number of pharmacological, psychological and alternative therapies are currently being used to treat patients with IBS; however, the efficacy of these therapies has not been proven. An extensive review of randomized, double-blind, placebo controlled drug trials performed between 1966 and 1988 by Klein (10) found that none of the studies provided sound statistical evidence to suggest that any of the medications were significantly beneficial in treating the symptoms of IBS. A similar lack of evidence exists for the effectiveness of treatment of other FGDs, such as functional dyspepsia or noncardiac chest pain. In Klein's review (10), most studies were flawed because of short treatment periods (one-half were less than four weeks' duration), poor operational definition of IBS, crossover design, and a short or no follow-up period. Likewise, a critical review of psychotherapies for IBS by Talley et al (11) found no one form of therapy to be definitely better than placebo and most of the studies to be flawed. Despite the lack of reliable controlled outcome data, there is a general consensus that both pharmacological and 


\section{COPYRIGHT PULSUS GROUP INC, D DO NOT COPY}

behavioural approaches can improve specific disease components such as altered bowel habits, abdominal pain and discomfort, and affective disease components.

\section{TREATMENTS TARGETED PRIMARILY AT ALTERED BOWEL HABITS AND GASTROINTESTINAL MOTILITY}

Bulking agents: Dietary fibre adds nondigestable bulk to stool, by both retaining water due to hydrophilic properties and serving as a substrate for microbial growth in the colon. By absorbing and adsorbing water, fibre both limits stool dehydration and normalizes stool consistency (12). Colonic transit time in both normal and constipated patients is reduced by dietary fibre at doses ranging from approximately 12 to $20 \mathrm{~g}(13)$. The rationale behind using fibre supplements in the treatment of functional gastrointestinal pain is both to normalize altered gut transit and to reduce abdominal pain by changing the mechanoelastic properties of the gut during contractions.

Prokinetics: Cisapride, a serotonin receptor agonist (5-hydroxytryptamine $\left._{4}\left[5 \mathrm{HT}_{4}\right]\right)$ and antagonist $\left(5 \mathrm{HT}_{3}\right)$ that increases acetylcholine release from the myenteric plexus, has been shown to increase lower esophageal sphincter pressure and the amplitude of esophageal contractions, accelerate gastric emptying of solids and liquids, increase small bowel motor activity, and accelerate colonic transit (presumably secondary to faster delivery of ileal contents into the cecum and right colon). The rationale behind using a prokinetic agent in the treatment of functional gastrointestinal pain and discomfort is that poor propagation of intestinal contents leads to distension of the hollow viscus, resulting in sensations of fullness and bloating.

The clinical utility of cisapride in patients with IBS has been studied in two placebo controlled studies. Van Outryve et al (14) conducted a randomized, double-blind, placebo controlled study in 69 constipation-predominant IBS patients. The dose of oral cisapride ranged from 2.5 to $10 \mathrm{mg}$ tid, and the study duration was 12 weeks. Stool frequency and number of days with normal stools increased for both cisapride and placebo groups by week 4 but continued to improve in the cisapride group and remained unchanged in the placebo group during weeks 8 to 12 . Abdominal pain and distention decreased in both groups by week 4 , but the reduction of symptoms was significantly greater in the cisapride group than in the placebo group by week 12 . The overall rating for response to treatment at week 12 was good or excellent in $71 \%$ versus $39 \%$ in the cisapride and placebo groups, respectively. The agent was well tolerated. Another study by Hurlimann et al (15) reported a reduction in bloating in patients with bloating-predominant IBS treated with oral cisapride ( $10 \mathrm{mg}$ tid) for four weeks compared with those treated with placebo $(\mathrm{P}<0.05)$.

The exact mechanism by which cisapride may improve IBS symptoms in a subset of patients remains unclear but may include increasing coordination of colonic peristaltic activity and reducing the sensory threshold for urge to defecate. Further well designed trials are needed to determine whether cisapride or similar compounds are beneficial for all patients with chronic constipation or only specific subgroups, and to determine the drug's long term efficacy.

Smooth muscle relaxants: Smooth muscle relaxants or so-called antispasmodics are thought to relieve abdominal symptoms by inhibiting intestinal smooth muscle contractions, thereby decreasing colonic motor activity. Agents included in this class are anticholinergics and calcium channel blockers. A recent meta-analysis by Poynard et al (16) of 26 randomized controlled trials with eight different drugs concluded that smooth muscle relaxants were significantly better than placebo for global assessment (62\% versus $35 \%$ ) and abdominal pain (64\% versus $45 \%)$. No improvement was detected for constipation or abdominal distention. When the eight drugs were analyzed separately, only three had efficacy in comparison with placebo - cimetropium bromide and dicyclomine bromide, which are antimuscarinic compounds; and octylonium, which is a quaternary ammonium derivative with calcium-antagonist properties. It is possible that these compounds work in a subset of patients, in whom enhanced, more frequent or prolonged intestinal motor activity contributes to symptoms. Alternatively, it is conceivable that the CNS effect of these compounds, which includes sedation, also plays a role in symptom relief in some patients.

\section{TREATMENTS TARGETED AT ABDOMINAL PAIN}

Low dose tricyclic antidepressants and anxiolytics: Antidepressants have been used for chronic pain because of their analgesic actions and antidepressant effects. The efficacy of antidepressants on global improvement in 138 IBS patients was assessed in an uncontrolled retrospective review by Clouse et al (17). Antidepressant agents used in descending order of frequency were amitryptiline (10 to $125 \mathrm{mg} /$ day), doxepin ( 10 to $100 \mathrm{mg} /$ day), amoxapine ( 25 to $200 \mathrm{mg} /$ day), alprazolam ( 0.25 to $2.25 \mathrm{mg} /$ day), thioridazine ( 10 to $40 \mathrm{mg} /$ day), trazadone ( 50 to $150 \mathrm{mg} /$ day), protriptyline ( 5 to $15 \mathrm{mg} /$ day) and imipramine (20 to $25 \mathrm{mg} /$ day). Global improvement occurred in $89 \%$ of the patients, and remission of symptoms in $61 \%$. Despite the limitations of the study, several interesting observations were made. First, with relation to symptom pattern, the response rate was greatest for pain-predominant IBS patients $(81 \%)$ compared with diarrhea-predominant $(60 \%)$ and constipation-predominant (51\%) subjects. Second, improvement and remission occurred at lower doses of antidepressants $(50 \mathrm{mg} /$ day for several of the tricyclic antidepressants). Third, the presence of psychiatric features did not influence clinical response. Despite the use of low doses, side effects including sedation and anticholinergic effects occurred in $30 \%$ of the patients (58\% requiring change to alternative antidepressant). As has been shown for chronic somatic pain conditions, the presence of psychiatric comorbidity did not influence clinical response. The definitive mechanism of action of antidepressants given in nonpsychiatric doses is not known, even though a possible attenuating effect on central arousal systems is an attractive hypothesis. 


\section{COPYRIGHT PULSUS GROUP INC, D DO NOT COPY}

Anxiolytic drugs, such as benzodiazepines, barbiturates or the newer class of $5 \mathrm{HT}_{1}$ receptor antagonists, including buspirone, show clinical effectiveness in selected patients, in particular when high levels of anxiety are present. However, the side effect profile and the development of tolerance of most of these compounds prohibit their use except on a short term basis in selected patients.

\section{EVOLVING THERAPIES}

It is difficult to evaluate current and evolving therapies without a definitive etiology or pathophysiology of FGD. For example, even though a compound has been developed or is being marketed as an antispasmodic, aimed at a peripheral target to decrease the contractility of smooth muscle, it may exert its therapeutic effect via supraspinal muscarinic or antimuscarinic effects on central autonomic control or pain perception. The same argument holds true for compounds aimed at different serotonin receptors, opioid receptors or tricyclic antidepressants.

Despite these considerations, it is possible to discuss evolving therapies and those that are in development under two main categories - those aimed at decreasing the transmission of viscerosensory information from the periphery to the brain (assuming a 'hypersensitive gut') and those aimed at decreasing the amplification of viscerosensory information by the brain (assuming a 'hypersensitive brain').

Approaches aimed at decreasing the transmission of viscerosensory information to the brain (the 'hypersensitive gut') - Attenuation of colonic motility: Phase II studies are currently under way to evaluate the effectiveness of a selective antagonist of the M3 muscarinic receptor subtype on IBS symptoms. The rationale behind this approach is that by blocking the muscarinic receptor subtype present on smooth muscle and by avoiding blockade of the predominant muscarinic receptor subtype in the CNS, a more effective inhibition of excessive colonic motility would be achieved without the dose-limiting CNS side effects of currently available antispasmodics.

Recently, evidence was provided for the potential usefulness of a $5 \mathrm{HT}_{4}$ antagonist (18). Its mechanism of action in the treatment of IBS symptoms is unknown (see below), similar to the mechanisms of most of the other compounds aimed at subtypes of the serotonin receptor. However, it has been proposed that the inhibitory effect of the compound on peristaltic intestinal motor activity may play a therapeutic role.

Visceral analgesics: Several compounds with presumed visceral analgesic action are currently being developed and evaluated for the treatment of IBS. Primary end-points in most recent studies are abdominal pain and discomfort.

Peripherally acting kappa opioid agonists have been developed in the hope of obtaining a visceral analgesic effect without the central side effects of conventional opioid drugs. One of these compounds, fedotozine, was evaluated in a European double-blind, randomized, placebo controlled multicentre trial; 277 patients were randomized to receive either oral fedotozine (30 mg tid) or placebo for six weeks
(19). During treatment, there was significantly greater improvement of abdominal pain intensity with fedotozine than with placebo. Regardless of the outcome of ongoing trials in the United States, the concept of a peripherally acting opioid without CNS side effects remains an attractive target.

Serotonin $\left(5 \mathrm{HT}_{3}\right)$ receptor antagonists have been identified in the CNS, and on postganglionic autonomic, enteric and sensory neurons. $5 \mathrm{HT}_{3}$ receptor antagonists have been shown to have antiemetic, and possibly anxiolytic and analgesic effects $(20,21)$. The antiemetic effects are presumed to be mediated by $5 \mathrm{HT}_{3}$ receptors on vagal afferent nerves in the upper gastrointestinal tract. The effect of $5 \mathrm{HT}_{3}$ receptor antagonists on rectal sensitivity and intestinal contractility has been studied in IBS patients. The $5 \mathrm{HT}_{3}$ receptor antagonist, granisetron, decreased rectal sensitivity measured by serial rectal balloon inflations with increasing volumes in a dose-dependent manner in IBS patients (22). The rectal postprandial motility index was reduced in a dose-dependent manner with granisetron, and the effect was likely to be mediated by an action of the compound on vagal afferent nerves in the upper gastrointestinal tract. In contrast, ondansetron, another $5 \mathrm{HT}_{3}$ receptor antagonist, had no effect on rectal sensitivity, rectal tone, colonic tone or fasting colonic motility index in diarrhea-predominant IBS patients or healthy subjects. A small, randomized, double-blind, placebo controlled crossover trial assessed the effect of oral ondansetron on bowel symptoms and intestinal transit in diarrhea-predominant IBS individuals. After treatment with ondansetron, there was a significant improvement in stool consistency but not in stool frequency, stool weight, abdominal pain and IBS symptom criteria (23). Similar to the concept of kappa opioid agonists, $5 \mathrm{HT}_{3}$ receptor antagonists remain a promising approach to the treatment of both bowel disorders and enhanced visceral sensitivity.

The long acting somatostatin analogue, octreotide, was shown in case report studies to be useful in treating visceral and somatic chronic pain syndromes. Octreotide was recently studied for its effect on afferent rectal sensation in controls and IBS patients. Subcutaneous injections of octreotide (approximately $100 \mathrm{mg}$ ) in normal individuals increase pressure and volume thresholds during rectal distention (24). In diarrhea-predominant IBS patients, octreotide was reported to increase discomfort volume thresholds to ramp distention in comparison with placebo and to shift the pressure-volume curve to the right, suggesting that octreotide increases compliance, thereby increasing the volume necessary to trigger a sensation. No direct effect on visceral afferent thresholds by octreotide was demonstrated in this study. The identification of multiple somatostatin receptor subtypes and the development of subtype-specific agonists may provide compounds with more selective effects on visceral sensation, without the side effects found in currently used, nonselective agonists.

Receptors for neurotransmitters involved in spinal pain transmission, ie, the $N$-methyl-D-aspartate receptor (glutamate receptor subtype), the neurokinin-1 receptor and the calcitonin gene-related peptide receptor, have become at- 
arug development for both somatic and tractive targets for drug development for both somatic and visceral pain. Antagonists for the neurokinin-1 and the $N$-methyl-D-aspartate receptor have been evaluated in animal models of somatic and visceral pain, while results from studies in humans are not yet available.

Approaches aimed at decreasing the amplification of viscerosensory information by the brain (the 'hypersensitive brain'): Drugs aimed at decreasing the amplification of viscerosensory information by the brain include modulators of the central corticotropin-releasing factor receptor and novel benzodiazepine derivatives. Effectiveness of several compounds for the treatment of experimental models of stress and anxiety has been demonstrated (25), while results from studies in humans are not yet available.

\section{SUMMARY AND CONCLUSIONS}

Considerable progress has been made within the past five years in the conceptualization of the pathophysiology and etiology of the various FGD. While little scientific evidence supports the usefulness of the most commonly prescribed medications for IBS and other FGD, evolving drug development will allow us to confirm or eliminate a scientific hypothesis (hypersensitive gut versus hypersensitive brain) and will hopefully provide effective therapies before the end of the century.

\section{REFERENCES}

1. Whitehead WE, Bosmajian L, Zonderman AB, Costa PT Jr, Schuster MM. Symptoms of psychological distress associated with irritable bowel syndrome. Comparison of community and medical clinical samples. Gastroenterology 1988;95:709-14.

2. Mayer EA, Gebhart GF. Basic and clinical aspects of visceral hyperalgesia. Gastroenterology 1994;107:271-93.

3. Locke GR, Talley NJ, Zinsmeister AR, Melton LJ. The irritable bowel syndrome and functional dyspepsia: familial disorders? Gastroenterology 1996;110:A26. (Abst)

4. Morris-Yates A, Talley NJ, Boyce PM, Nandurkar S, Andrews G. Evidence of a genetic contribution to functional bowel disorder. Am J Gastroenterol 1998;93:1311-7.

5. Plotsky PM, Meaney MJ. Early, postnatal experience alters hypothalamic corticotropin-releasing factor (CRF) mRNA, median eminence CRF content and stress-induced release in adult rats. Brain Res Mol Brain Res 1993;18:195-200.

6. Caldji C, Tannenbaum B, Sharma S, Francis D, Plotsky PM, Meaney MJ. Maternal care during infancy regulates the development of neural systems mediating the expression of fearfulness in the rat. Proc Natl Acad Sci USA 1998;95:5335-40.

7. Drossman DA, Leserman J, Nachman G, et al. Sexual and physical abuse in women with functional or organic gastrointestinal disorders. Ann Intern Med 1990;113:828-33.
INC, DONOT COPY

oomey TC, Hu Y. Health status by gastrointestinal diagnosis and abuse history. Gastroenterology 1996;110:997.

9. Leserman J, Li Z, Drossman DA, Toomey TC, Nachman G, Glogau L. Impact of sexual and physical abuse dimensions on health status: development of an abuse severity measure. Psychosom Med 1997;59:152-60.

10. Klein KB. Controlled treatment trials in the irritable bowel syndrome: a critique. Gastroenterology 1988;95:232-41.

11. Talley NJ, Owen BK, Boyce P, Paterson K. Psychological treatments for irritable syndrome: a critique of controlled treatment trials. Am J Gastroenterol 1996;91:277-83.

12. Sperling RM, McQuaid KR. Rational medical therapy of functional GI disorders. In: Olden KW, ed. Handbook of Functional Gastrointestinal Disorders. New York: Marcel Dekker, Inc, 1996:269-328.

13. Muller-Lissner SA. Effect of wheat bran on weight of stool and gastrointestinal transit time: a meta analysis. Br Med J (Clin Res Ed) 1988;296:615-7.

14. Van Outryve M, Milo R, Toussaint J, Van Eeghem P. "Prokinetic" treatment of constipation-predominant irritable bowel syndrome: a placebo-controlled study of cisapride. J Clin Gastroenterol 1991;13:49-57.

15. Hurlimann S, Shorvon P, Misiewicz JJ. Effects of cisapride on symptoms and ileo-caecal transit in patients with bloated bowel syndrome. Gastroenterology 1992;102:460. (Abst)

16. Poynard T, Naveau S, Mory B, Chaput JC. Meta-analysis of smoooth muscle relaxants in the treatment of irritable bowel syndrome. Aliment Pharmacol Ther 1994;8:499-510.

17. Clouse RE, Lustman PJ, Geisman RA, Alpers DH. Antidepressant therapy in 138 patients with irritable bowel syndrome: a five-year clinical experience. Aliment Pharmacol Ther 1994;8:409-16.

18. Houghton LA, Jackson NA, Whorwell PJ, et al. 5HT4 Antagonism in irritable bowel syndrome (IBS): Effect of SB-207266-A on rectal sensitivity and small bowel transit. Gut 1997;41 (Suppl 3):A26. (Abst)

19. Dapoigny M, Abitbol JL, Fraitag B. Efficacy of peripheral kappa agonist fedotozine versus placebo in treatment of irritable bowel syndrome. A multicenter dose-response study. Dig Dis Sci 1995;40:2244-9.

20. Hesketh PJ, Murphy WK, Lester EP, et al. GR 38032F (GR-C507/75): a novel compound effective in the prevention of acute cisplatin-induced emesis. J Clin Oncol 1989;7:700-5.

21. Jones BJ, Oakley NR, Tyers MB. The anxiolytic activity of GR $38032 \mathrm{~F}$, a $5 \mathrm{HT}_{3}$ receptor antagonist, in the rat and cynomolgus monkey. Br J Pharmacol 1987;90:88.

22. Prior A, Read NW. Reduction of rectal sensitivity and post-prandial motility by granisetron, a $5 \mathrm{HT}_{3}$-receptor antagonist, in patients with irritable bowel syndrome. Aliment Pharmacol Ther 1993;7:175-180.

23. Steadman CJ, Talley NJ, Phillips SF, Zinsmeister AR. Selective 5-hydroxytryptamine type 3 receptor antagonism with ondansetron as treatment for diarrhea-predominant irritable bowel syndrome: a pilot study. Mayo Clin Proc 1992;67:732-8.

24. Hasler WL, Soudah HC, Owyang C. Somatostatin analog inhibits afferent response to rectal distention in diarrhea-predominant irritable bowel patients. J Pharmacol Exp Ther 1994;268:1206-11.

25. Chalmers DT, Lovenberg TW, Grigoriadis DE, Behan DP, De Souza EB. Corticotrophin-releasing factor receptors: from molecular biology to drug design. Trends Pharmacol Sci 1996;17:166-72. 


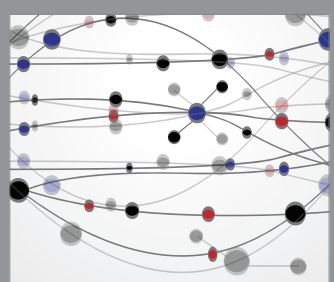

The Scientific World Journal
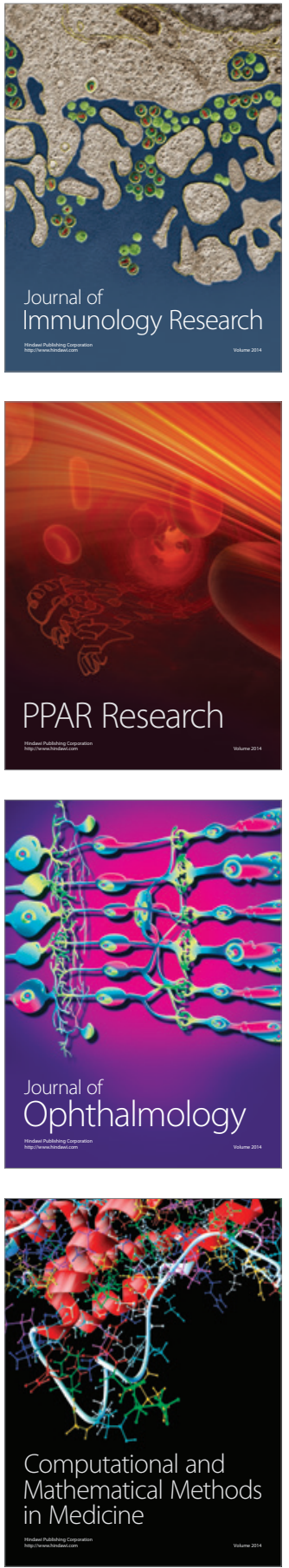

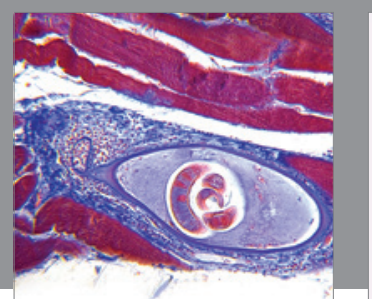

Gastroenterology Research and Practice

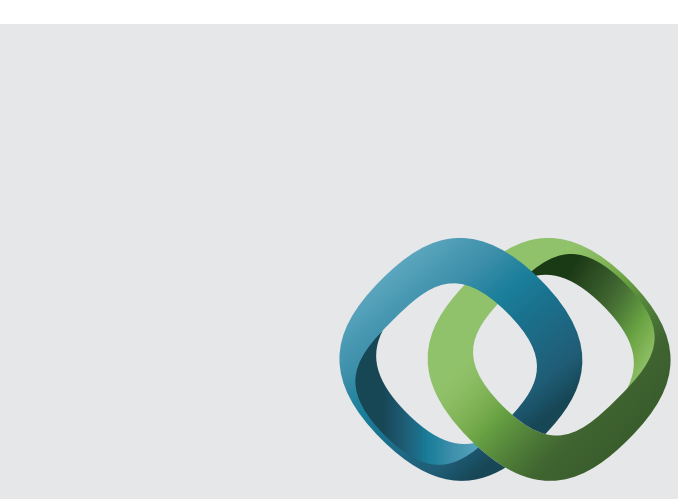

\section{Hindawi}

Submit your manuscripts at

http://www.hindawi.com
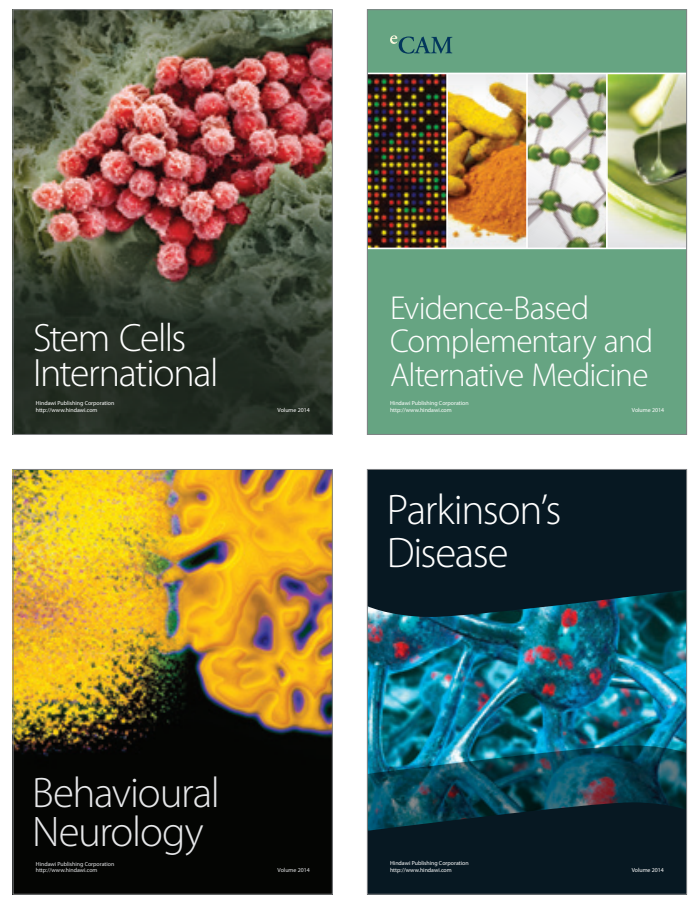
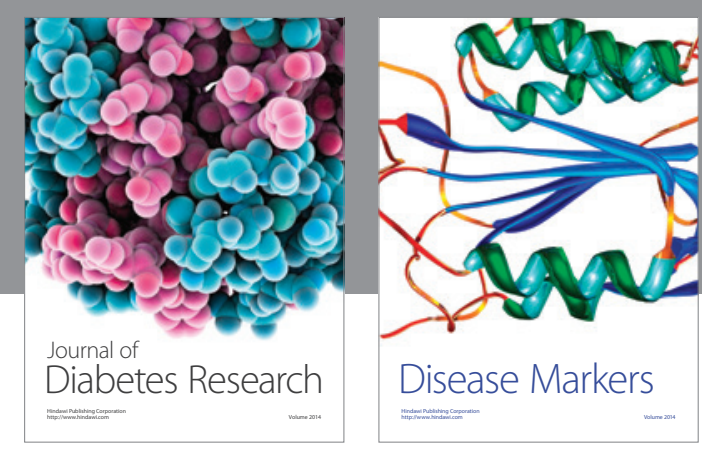

Disease Markers
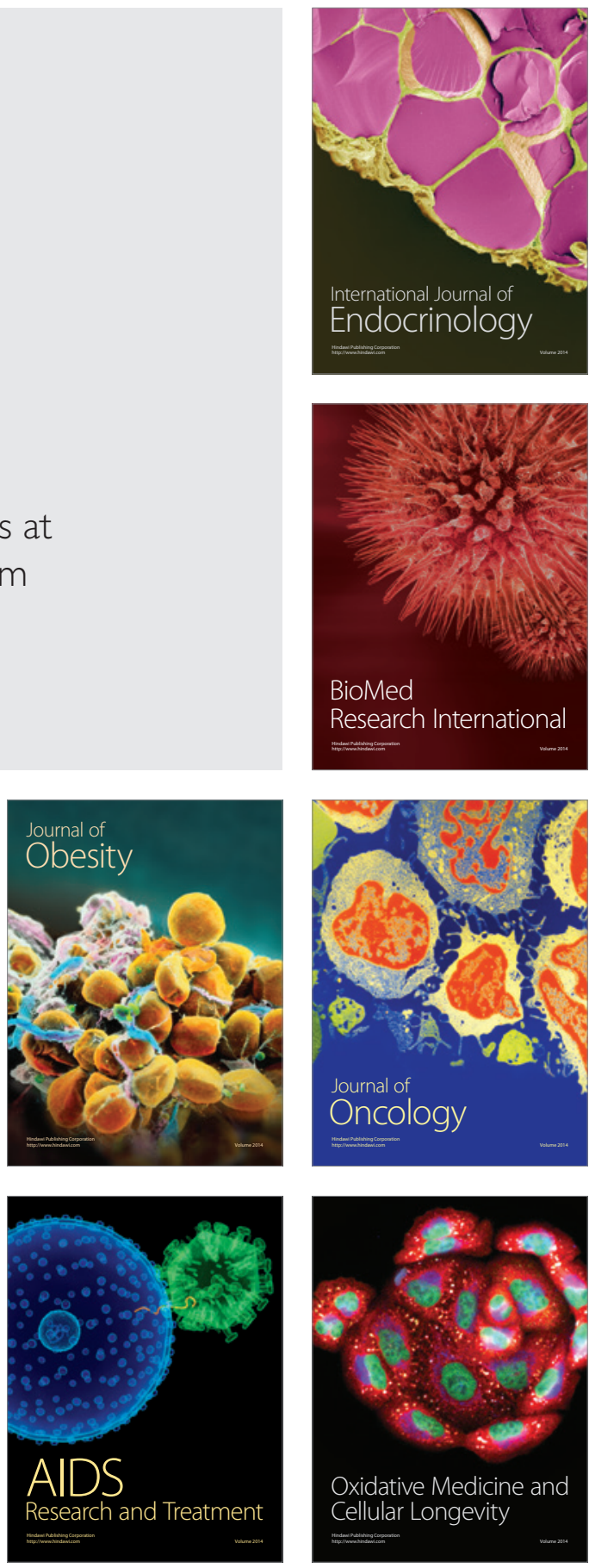